\title{
Evolutionary two-step
}

\author{
The march from an Archaean microbial world to the modern reign of more complex life was slow but \\ not steady. Instead, the rise of the animals may have resulted from an intricate back-and-forth between \\ evolving life and the Earth's environment.
}

Oxygen in the atmosphere and ocean is the basis of current life on Earth. Yet for a large fraction of Earth's history, oxygen was extremely scarce and so was multicellular life. The production and release of free oxygen, first by cyanobacteria and then by algae, was key to the evolution of eukaryotic cells - cells that contain a membrane-bound nucleus and form the building blocks of all complex multicellular organisms. In a web focus published with this issue (http://www. nature.com/ngeo/focus/oygenation-earth/ index.html), we explore some of the twists and turns in the long road to an oxygen-rich ocean-atmosphere system on Earth.

The history of oxygen on Earth predates the evolution of most animals by a couple of billion years. In the ocean's surface waters, photosynthetic microbes began to churn out free oxygen as early as 3 billion years ago, suggests a Letter on page 283, and appreciable levels of atmospheric oxygen have been inferred for the same time ${ }^{1}$. However, another few hundred million years passed before microbes were making free oxygen in sufficient quantities to overcome both abiotic sinks and the enterprising bacteria that quickly developed the ability to use any available free oxygen ${ }^{2}$. When oxygen production exceeded immediate consumption, oxygen could accumulate in the surface oceans and eventually in the atmosphere, too. The more permanent rise in atmospheric oxygen concentrations at the time of the Great Oxidation Event about 2.4 billion years ago was striking. Nevertheless, oxygen levels only reached about 0.1 to $0.2 \%$ of today's concentrations. Though fluctuating along the way, surface oxygen concentrations stabilized at about $10 \%$ of present levels between about 1,800 to 700 million years ago. The deep oceans, however, remained anoxic throughout this interval.

If oxygen was the missing ingredient for the evolution of eukaryotic cells and prolific complex life forms, then the earliest signs of multicellular life might be expected to have appeared less than 1,800 million years ago, as oxygen concentrations climbed. However, the earliest known evidence for multicellular organisms (up to $12 \mathrm{~cm}$ in length!) was found in 2.1-billion-year-old rocks ${ }^{3}$. They were

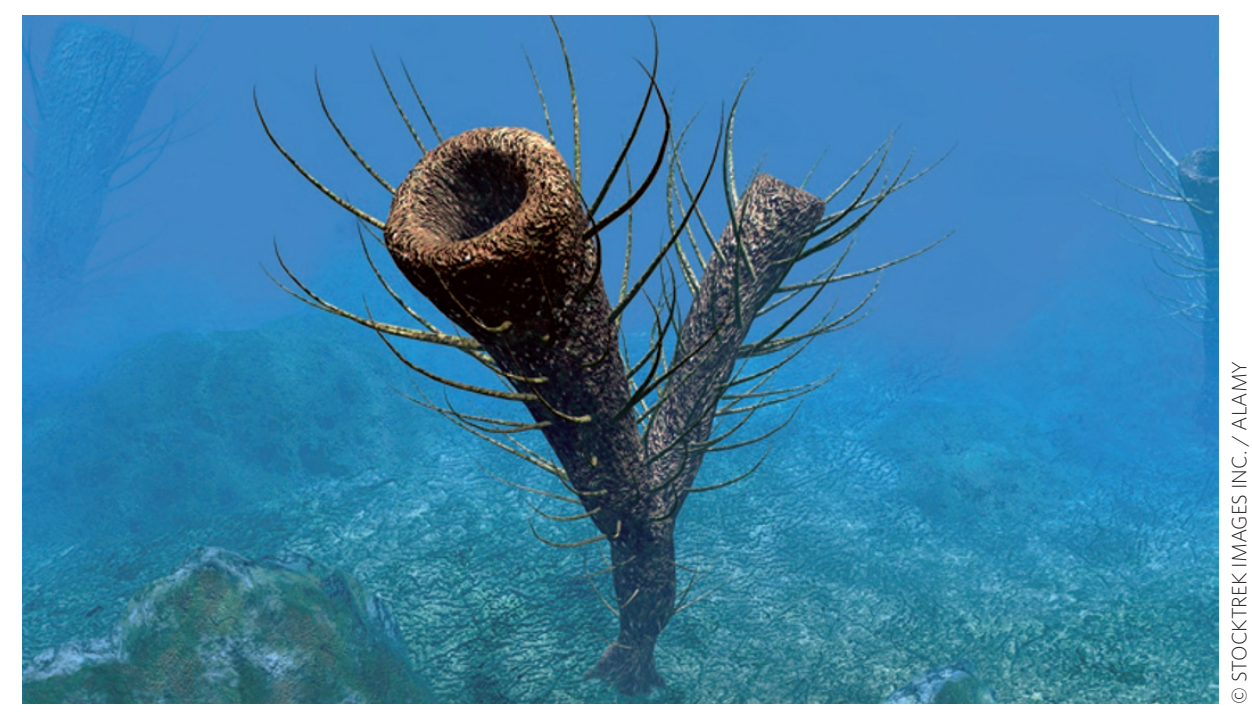

not animals, but were most likely aerobic. If so, they were able to respire despite low, and potentially even declining, oxygen concentrations at this time ${ }^{2}$.

Aerobic respiration in low oxygen concentrations is not without analogues in the modern world. Whereas larger and more mobile animals require significant concentrations of oxygen, smaller or simpler creatures may have lower oxygen requirements than was once thought. Modern sponges, for example, can survive at oxygen concentrations as low as $0.5 \%$ of present levels ${ }^{4}$. At least in shallower waters, sponges should therefore have been comfortable at the oxygen concentrations found throughout much of the Neoproterozoic eon.

In a Review on page 257, Lenton and colleagues suggest that the evolution of larger, rapidly sinking cells, and then of sponges, would have helped get oxygen to the sea floor by reducing the consumption of oxygen at the surface by decay and allowing it to mix to depth. Redox conditions in the deep ocean were highly variable until at least 550 million years ago, and most of the organisms that today scavenge for food at the sea floor had yet to evolve. Thus any large particles made of organic carbon that sank out of surface waters and reached the sediments should have been buried at a higher rate than in the modern oceans $s^{5}$. This drawdown of carbon, in turn, could have promoted the widespread
Snowball Earth glaciations that probably began about 720 million years ago.

Ice sheets extending to the tropics, as reconstructed for the Snowball Earth glaciations, would not have benefitted the expansion of complex cells. The meltdown, however, is a different matter: sediments eroded by the ice sheets delivered massive quantities of nutrients to the oceans, which stimulated productivity ${ }^{2}$. The sediments also carried elements such as calcium, magnesium and strontium. These elements are not vital nutrients, but they are the basis for skeletons and shells; animals with these hard parts spread quickly in the early Cambrian period, from about 541 million years ago. The Cambrian radiation introduced almost all the phyla that make up life today.

Reconstructions of Earth's earliest history are necessarily uncertain, and often contentious. But if this sequence of events is confirmed, then the evolution of eukaryotic, larger cells - helped along by rising oxygen levels - may have helped bring oxygen to the depths of the oceans and paved the way for the dawn of modern life.

\section{References}

1. Crowe, S. A. et al. Nature 501, 535-538 (2013).

2. Lyons, T., Reinhard, C. \& Planavsky, N. Nature 506, 307-315 (2014) 3. El Albani, A. et al. Nature 466, 100-104 (2010).

4. Mills, D. B. et al. Proc. Natl Acad. Sci. USA http://dx.doi.org/10.1073/ pnas.1400547111 (2014).

5. Tziperman, E. et al. Proc. Natl Acad. Sci. USA 108, 15091-15096 (2011). 